\title{
American Board of Family Medicine's Physicians Quality Reporting System Registry
}

In 2006, Congress passed the Tax Relief and Health Care Act, which included provisions requiring the Centers for Medicare and Medicaid (CMS) to establish a quality reporting system, the Physicians Quality Reporting Initiative (now called the Physicians Quality Reporting System), for eligible health care providers that would include financial incentives for participants. ${ }^{1}$ This system initially used a fairly cumbersome set of "G codes" for reporting quality indicators as part of the claims process. Subsequently, the Medicare, Medicaid, and SCHIP Extension Act of 2007 and the Medicare Improvements for Patients and Providers Act of 2008 provided an alternative registry method for reporting quality indicators in the incentive program. ${ }^{1}$ Under the registry method, quality organizations could apply to become approved registries and submit data on behalf of their clients. The application process included interviews by CMS staff and a description of the organization's proposed registry architecture and structure. The first registries approved became active during the second half of 2008. The American Board of Family Medicine (ABFM) was the only medical specialty board approved in the initial group of registries.

ABFM built on its Diabetes Performance in Practice Module (PPM) when implementing its registry. ${ }^{2}$ The registry program allows participating organizations to use "measures groups" for reporting quality information, ${ }^{3}$ and the indicators in the diabetes measures group correspond closely to those included in ABFM's Diabetes PPM (eg, measurement of glycosylated hemoglobin and low-density lipoprotein levels, foot examination). ${ }^{4}$ Because the registry started in mid-2008, Diplomates who participated reported data for only the last 6 months of the year. In 2009 and 2010, participants collected patient information for the whole year. Participants are required to report measures information for 30 diabetic patients over the year, and the patients they select must include at least 2 Medicare Part B recipients. ABFM provides tem- plates that Diplomates use for extracting their measures information; they then submit these data (deidentified) online via a secure connection to ABFM servers. ABFM subsequently submits these data on behalf of the Diplomates using submission templates specified by CMS. ${ }^{5}$

The financial incentives for participants have been potentially substantial. In 2008, the incentive consisted of $1.5 \%$ of all a participant's Medicare billings; the incentive rose to $2 \%$ in 2009 , fell back to $1.5 \%$ for 2010, and will equal $1 \%$ in 2011. Medicare does not report to the registries the amounts paid to participants, but anecdotal information suggests that ABFM registry participants have averaged bonuses of approximately \$1200 (James Puffer, MD, personal communication, 9 March 2011.)

The registry has experienced varied participation since its inception. Three hundred eight-three Diplomates submitted data in 2008, 722 participants in 2009, and 867 participants in 2010 .

Our registry process includes an audit of $3 \%$ of participants' submissions. To conduct the audit, ABFM selects at random $3 \%$ of the participants and contracts with a third party to audit the charts used for abstracting and reporting performance data. The audit process consists of comparing actual chart entries with the data submitted to the registry. These reviews have indicated high concordance between the reported and chart data: the 2008 submissions indicated $96 \%$ concordance between the registry submission and medical record data and the 2009 audit revealed approximately 94\% agreement. The 2010 audit is still underway and won't be finalized until the end of June.

In developing the registry, ABFM has striven to provide enhanced value for Diplomates who participate. Because the data elements correspond closely to those in the Diabetes PPM, Diplomates can choose to use their registry submissions for both the Physicians Quality Reporting System program and for the patient data required for the Diabetes PPM. Participants who select this option can use 1 year's Physi- 
cians Quality Reporting System data as their PPM preintervention submission, and the next year's Physicians Quality Reporting System data can be used for their PPM postintervention submission. This allows a Diplomate to accomplish three important tasks with the same activities: 2 years of Physicians Quality Reporting System participation and satisfaction of their Maintenance of Certification for Family Physicians part IV requirement.

\section{Conclusions}

ABFM engaged in the Physicians Quality Reporting System program to provide a service to our Diplomates (ABFM does not charge for Diplomate participation in the registry) and to enhance the value of Maintenance of Certification for Family Physicians in Diplomates' ongoing professional activities. We hope more Diplomates will take advantage of this process!

\section{References}

1. US Department of Health and Human Services, Centers for Medicare and Medicaid Services. Overview.
Physicians Quality Reporting System, formerly known as the Physicians Quality Reporting Initiative. Available at: http://www.cms.gov/Physicians Quality Reporting System/. Accessed 1 March 2011.

2. American Board of Family Medicine. Maintenance of Certification. Part IV-performance in practice. Available at: https://www.theabfm.org/moc/part4.aspx. Accessed 1 March 2011.

3. Centers for Medicare and Medicaid Services. 2009 Physicians Quality Reporting Initiative measures list. Baltimore, MD: Center for Medicare and Medicaid Services; 2009.

4. Centers for Medicare and Medicaid Services. Getting started with 2009 Physicians Quality Reporting Initiative Reporting of Measures Groups. Baltimore, MD: Centers for Medicare and Medicaid Services; 2009.

5. Centers for Medicare and Medicaid Services. Physicians Quality Reporting Initiative 2009 Registry XML Specifications. Baltimore, MD: Centers for Medicare and Medicaid Services; 2009.

Michael Hagen, MD American Board of Family Medicine Lexington, KY 